\title{
The Effect of Nanoparticles with Sorption Capacity on the Bioaccumulation of Divalent lons by Aquatic Plants
}

\author{
Monika Asztemborska ${ }^{1}$ (D) Marcin Bembenek ${ }^{1} \cdot$ Małgorzata Jakubiak $^{1} \cdot$ Romuald Stęborowski $^{1}$. \\ Grażyna Bystrzejewska-Piotrowska'
}

Received: 17 October 2017/Revised: 12 February 2018/Accepted: 24 March 2018/Published online: 6 April 2018

(C) The Author(s) 2018

\begin{abstract}
Wide utilization of nanotechnologies results in the release of nanomaterials into the environment. Considering the sorption capacity of nanoparticles (NPs) and their growing concentration in aquatic environment, the modification of metal ion uptake by direct NP-metal ion reaction, including adsorption of ions onto the surface of the NPs, can be assumed. The aim of the study was to characterize the sorption capacity of zinc and titanium oxide nanoparticles $\left(\mathrm{TiO}_{2} \mathrm{NPs}_{25}\right.$ and $100 \mathrm{~nm}$; $\mathrm{ZnO}$ NPs 50 and $100 \mathrm{~nm}$ ) and to examine the bioaccumulation of $\mathrm{Zn}(\mathrm{II})$ and $\mathrm{Sr}(\mathrm{II})$ ions by aquatic plants Salvinia natans and Elodea canadensis in the presence of the above-mentioned NPs. The results have shown that NPs can adsorb metal ions present in the water. It was also observed that the sorption efficiency strongly depends on the: (1) concentrations of NPs and increase in the range $0.01-5 \mathrm{~g} \mathrm{~L}^{-1}$; (2) $\mathrm{pH}$ - the highest sorption efficiency was observed at $\mathrm{pH} 8$; (3) chemical composition of the medium (presence of humic substances at $0.01 \mathrm{~g} \mathrm{~L}^{-1}$ increased the sorption efficiency of $\mathrm{Sr}$ on $\mathrm{TiO}_{2}$ $25 \mathrm{~nm}$ from 10 to 50\%). Under some conducive conditions, even $90 \%$ of $\mathrm{Zn}$ (II) ions can be removed from a solution through sorption using $\mathrm{ZnO}$ nanoparticles. Bioaccumulation of $\mathrm{Zn}(\mathrm{II})$ and $\mathrm{Sr}(\mathrm{II})$ ions by S. natans and E. canadensis was modified in the presence of investigated NPs. Bioaccumulation of $\mathrm{Sr}$ in E. canadensis and S. natans was reduced by NPs of $\mathrm{ZnO} 100 \mathrm{~nm}$ at concentration $1 \mathrm{~g} \mathrm{~L}^{-1}$ of about 49 and 23\%, respectively. Bioavailability of $\mathrm{Zn}$ was the most affected by $\mathrm{NPs}$ of $\mathrm{ZnO} 100 \mathrm{~nm}$ at $1 \mathrm{~g} \mathrm{~L}^{-1}$. Bioaccumulation of $\mathrm{Zn}$ in E. canadensis was reduced by $68 \%$. An opposite effect was found for S. natans - addition of ZnO NPs caused an increase of $\mathrm{Zn}$ bioaccumulation by $45 \%$.
\end{abstract}

Keywords $\mathrm{TiO}_{2}$ nanoparticles $\cdot \mathrm{ZnO}$ nanoparticles $\cdot$ Sorption $\cdot$ Aquatic plants $\cdot$ Salvinia natans, Elodea canadensis

\section{Introduction}

Achievements in the area of nanoscience and nanotechnology find practical applications in many fields of the industry and in daily life. Nanoparticles (NPs), up to $100 \mathrm{~nm}$ large, compared to other materials, have unique physicochemical properties resulting from a high ratio of surface area to volume or weight and exhibit unusual interactions with the media (Alkilany and Murphy 2010; Bystrzejewska-Piotrowska et al. 2009). One of the side effects of wide utilization of nanotechnologies is the release of nanomaterials into the environment. Therefore,

Monika Asztemborska

asztemborska@biol.uw.edu.pl

1 Isotope Laboratory, Faculty of Biology, University of Warsaw, Miecznikowa 1, 02-096, Warsaw, Poland there is a growing need to study the diverse aspects of the presence of NPs in the environment. The focus of the researchers was mainly on the toxicity of NPs toward various kinds of organisms from a biomedical (Zoroddu et al. 2014; Yang et al. 2016) and ecotoxicological (Baker et al. 2014; Ma et al. 2010; Książyk et al. 2015; Thwala et al. 2016) perspective. Some studies are focused on the bioaccumulation of NPs by organisms (BystrzejewskaPiotrowska et al. 2012a; Asztemborska et al. 2014; Asztemborska et al. 2015a, b; Jakubiak et al. 2014; Jiménez-Lamana et al. 2016). However, investigation of direct interaction of NPs with living organisms does not provide complete information on real threat to the environment. Besides the toxicity, the influence of NPs on the chemical and physical behavior of soil or water components must also be considered. One of the possible effects caused by NPs is modification in the uptake of metal ions and other 
substances. It can be achieved by direct NP-metal ion reaction, including adsorption of ions onto the surface of NPs. Another effect is the influence on the transport systems of organisms by forming new, large-sized pores and routes, which increases the uptake of compounds or their adsorption onto the surface of the roots, resulting in inhibition of the uptake. The effect of NPs on the uptake of xenobiotics was documented in the literature. Baun et al. (2009) have found that the aggregates of nano-C60 (Buckminster fullerenes) influence the toxicity of organic compounds for algae Pseudokirchneriella subcapitata and crustaceans Daphnia magna. Bioaccumulation and toxicity of cadmium, zinc (Tan and Wang 2014), and copper (Fan et al. 2011) by D. magna are modified by titanium dioxide NPs. Nanoparticles of $\mathrm{TiO}_{2}$ enhance the uptake of phenanthrene by Scapharca subcrenata (Tian et al. 2014) and the accumulation of cadmium (Zhang et al. 2007) and arsenate (Sun et al. 2007) in carp.

One of the possible explanations for the modification of bioaccumulation by NPs is their sorption capacity. For example, carbon nanotubes show a high capacity for the adsorption of toxic metals such as $\mathrm{Pb}^{2+}, \mathrm{Cu}^{2+}$, and $\mathrm{Cd}^{2+}$ (Li et al. 2003). Saleh (2016) have demonstrated the ability of nanocomposites of carbon nanotubes and silica nanoparticles for the adsorption of $\mathrm{Pb}(\mathrm{II})$. Magnetite nanoparticles were investigated by Giraldo et al. 2013 as sorbents for $\mathrm{Pb}(\mathrm{II}), \mathrm{Cu}(\mathrm{II}), \mathrm{Zn}(\mathrm{II})$, and $\mathrm{Mn}(\mathrm{II})$. Adsorption was strongly influenced by $\mathrm{pH}$ and temperature, and the effect depended on the metal ion considered. Modified magnetite nanoparticles were applied for the adsorption of precious metals $\mathrm{Pd}(\mathrm{IV}), \mathrm{Au}(\mathrm{III}), \mathrm{Pd}(\mathrm{II}), \mathrm{Ag}(\mathrm{I})$ (Yen et al. 2017), $\mathrm{Cu}$ (II) (Liu et al. 2016), and $\mathrm{Hg}$ (II) (Wang et al. 2016a, b). Mesoporous NiO nanoparticles find application in the adsorption of $\mathrm{Cr}(\mathrm{VI})$ (Behnajady and Bimeghdar, 2014). Mahdavi et al. (2013) investigated on the removal of heavy metal ions $(\mathrm{Cd}(\mathrm{II}), \mathrm{Cu}(\mathrm{II}), \mathrm{Ni}(\mathrm{II})$, and $\mathrm{Pb}(\mathrm{II}))$ by oxide metal nanoparticles: $\mathrm{TiO}_{2}, \mathrm{MgO}$, and $\mathrm{Al}_{2} \mathrm{O}_{3}$. Among them, $\mathrm{MgO}$ nanoparticles were indicated as the most promising sorbents. Adsorption of divalent ions of $\mathrm{Pb}, \mathrm{Cd}$, $\mathrm{Cu}, \mathrm{Ni}$, and $\mathrm{Zn}$ to $\mathrm{TiO}_{2}$ nanoparticles and $\mathrm{TiO}_{2}$ bulk particles was studied as a function of the particle size, concentration, and exhaustion by Engates and Shipley (2011). Results confirmed that $\mathrm{TiO}_{2}$ nanoparticles are good sorbents of metal ions; during the first-adsorption cycle, $100 \%$ of $\mathrm{Pb}, 99 \%$ of $\mathrm{Cd}$ and $\mathrm{Zn}$, and $68 \% \mathrm{Cu}$ were adsorbed. Utilization of $\mathrm{ZnO}$ nanoparticles as an adsorbent of $\mathrm{Zn}$ (II), $\mathrm{Cd}(\mathrm{II})$, and $\mathrm{Hg}$ (II) was examined by Sheela et al. (2012). The sorption capacities of investigated NPs were 357, 387, and 714 for $\mathrm{Zn}, \mathrm{Cd}$, and $\mathrm{Hg}$, respectively. Asztemborska et al. (2016) have shown that alumina nanoparticles $\left(\mathrm{Al}_{2} \mathrm{O}_{3}\right.$ $\mathrm{NPs}$ ) have the ability to adsorb $\mathrm{Sr}$, and to a lesser extent, cesium (sorption efficacy was 40 and $20 \%$ for $\mathrm{Sr}$ and $\mathrm{Cs}$, respectively). However, contrary to expectations, $\mathrm{Al}_{2} \mathrm{O}_{3}$
NPs did not affect the mycoextraction of radioisotopes by the mycelia of Pleurotus eryngii. In a medium containing $P$. eryngii mycelia and NPs, concurrent processes, such as accumulation of radionuclides, accumulation of NPs, and sorption of radionuclides on the nanoparticle surfaces, can be distinguished.

Identification of aquatic environment as one of the most exposed to contamination with NPs enforces the extensive study of various effects of nano-level substances with organisms. One of the possible interactions is the modification of ion uptake by organisms as an effect of the sorption capacity of NPs. The aims of the study were: (1) to characterize the sorption capacities of zinc and titanium oxide nanoparticles (to find the influence of particle size and concentration, sorption temperature, $\mathrm{pH}$, and time on the adsorption efficiency) and (2) to examine the bioaccumulation of $\mathrm{Zn}$ (II) and $\mathrm{Sr}(\mathrm{II})$ ions by $S$. natans and Elodea canadensis in the presence of metal oxide nanoparticles.

\section{Materials and Methods}

\section{Reagents}

Nanoparticles of $\mathrm{TiO}_{2}$ (particle sizes $25 \mathrm{~nm}$ (surface area $>14.0 \mathrm{~m}^{2} / \mathrm{g}$ ) and $100 \mathrm{~nm}\left(\right.$ surface area $\left.45-55 \mathrm{~m}^{2} / \mathrm{g}\right)$ ) and $\mathrm{ZnO}$ [particle sizes $50 \mathrm{~nm}$ (surface area $>10.8 \mathrm{~m}^{2} / \mathrm{g}$ ) and $100 \mathrm{~nm}$ (surface area $15-25 \mathrm{~m}^{2} / \mathrm{g}$ )] were purchased from Sigma-Aldrich. In more detail, nanoparticles were characterized elsewhere (Baek and An 2011; Sadiq et al. 2011; Bystrzejewska-Piotrowska et al. 2012b). The stock solution was prepared by mixing $100 \mathrm{mg}$ of solid NPs and $100 \mathrm{~mL}$ of deionized water to obtain a final concentration of $1 \mathrm{~g} \mathrm{~L}^{-1}$. To achieve the concentration required for the experiments, a proper dilution of the stock solution was done. All solutions were freshly prepared and sonicated before experiments.

The $\mathrm{Zn}$ and $\mathrm{Sr}$ stock solutions were obtained by dissolving $100 \mathrm{mg}$ of $\mathrm{ZnCl}_{2}$ or $\mathrm{SrCl}_{2}$ in water $(100 \mathrm{~mL})$ to obtain a final concentration of $1 \mathrm{~g} \mathrm{~L}^{-1}$. Radioactive isotopes of $\mathrm{Zn}\left({ }^{65} \mathrm{Zn}\right)$ and $\mathrm{Sr}\left({ }^{90} \mathrm{Sr}\right)$ with activities 0.1 and $1 \mathrm{MBq}$, respectively, were purchased from Polatom (Otwock, Poland) and these were used as isotope tracers. $\mathrm{Zn}$ and $\mathrm{Sr}$ were present in all experimental variants at a constant concentration of $0.01 \mathrm{mg} \mathrm{L}^{-1}$ with an activity of $1 \mathrm{kBq} \mathrm{L}^{-1}$.

\section{Adsorption Experiments}

To characterize the sorption of $\mathrm{Zn}$ and $\mathrm{Sr}$ by NPs, experiments were performed under controlled conditions. In a $50-\mathrm{mL}$ vessel, a fixed amount of metal ions and an 
appropriate amount of NPs were added; the final volume of the experimental solution was $10 \mathrm{~mL}$. All experimental solutions were continuously agitated on an orbital shaker $\left(120 \mathrm{rpm}, 25^{\circ} \mathrm{C}\right)$. During the first step of experiment, several different concentrations of NPs were applied: $0.01-8 \mathrm{~g} \mathrm{~L}^{-1}$. For selected NP concentration $(0.1$ and $\left.1 \mathrm{~g} \mathrm{~L}^{-1}\right)$, sorption experiments were performed at variable time (0-24 h). Next, using $1 \mathrm{~g} \mathrm{~L}^{-1}$ NPs and sorption time of $15 \mathrm{~min}$, the influence of temperature $\left(5-90^{\circ} \mathrm{C}\right)$ and $\mathrm{pH}$ (2-10) on sorption efficiency was investigated. Finally, sorption experiments were performed with the addition of $0.01 \mathrm{~g} \mathrm{~L}^{-1}$ humic acids (Sigma-Aldrich; solution in deionized water) to evaluate the influence of organic matter on the sorption capacity of NPs (sorption time $15 \mathrm{~min}$ and $24 \mathrm{~h}$ ). All experimental series included reference samples, containing $\mathrm{Zn}$ or $\mathrm{Sr}$ ions without any NPs, used for the calculation of sorption capacity of NPs. After finishing the sorption, solutions were centrifuged (30 min; 16,000 rpm) and analyzed for the radioactivity of radioisotopes.

\section{Bioaccumulation Studies}

Plants used for bioaccumulation studies-adult $S$. natans and E. canadensis - obtained from the Botanical Garden of the Warsaw University, were cultivated in containers with solution containing metal oxide nanoparticles at 0.1 and $1 \mathrm{~g} \mathrm{~L}^{-1}$ and $\mathrm{Zn}$ or $\mathrm{Sr}$ at $0.01 \mathrm{mg} \mathrm{L}^{-1}$ under controlled conditions for 8 days. Reference cultivation with $\mathrm{Zn}$ or $\mathrm{Sr}$ ions without any NPs was carried out in parallel. Salvinia natans plants were cultivated in containers with $20 \mathrm{~mL}$ of experimental solution (five plants per container). The cultivation of $E$. canadensis was conducted in $100 \mathrm{~mL}$ of solution (one plant per container). After finishing the bioaccumulation experiments, plants were rinsed with deionized water, dried, homogenized, and analyzed for the radioactivity of radioisotopes.

\section{Radioactivity Measurements}

The activities of $\mathrm{Zn}$ in powdered plant samples of mycelium were determined using a low-background coaxial high-purity germanium detector (model GC1520; Canberra Industries, Zellik, Belgium). The relative efficiency of this detector for the ${ }^{60} \mathrm{Co}$ background lines at $1332 \mathrm{keV}$ was $18.0 \%$, the resolution (FWHM) was $1.74 \mathrm{keV}$, and the measurement time of each sample continued for over $3 \mathrm{~h}$. Energy and efficiency calibrations were carried out using a reference material from the International Atomic Energy Agency (Vienna, Austria): IAEA-156. The activities of $\mathrm{Sr}$ were measured in a Geiger-Muller detector equipped with an SPF-32 plastic scintillation probe, and 5-cm-thick lead housing. Measurements of each sample were carried out within $10 \mathrm{~min}$ and these were referred to reference material with a known activity of ${ }^{90} \mathrm{Sr}$. The activities of liquid samples were measured in a Beckman LS6000 scintillation counter. For this purpose, $1 \mathrm{~mL}$ of sample was diluted with $5 \mathrm{~mL}$ of scintillation cocktail Rotiszint eco plus (Carl Roth $\mathrm{GmbH}$ ), placed in a $20-\mathrm{mL}$ plastic vial (Sarstedt) and counted within $10 \mathrm{~min}$ in CPM (counts per minute).

\section{Data Analysis}

All experiments were performed in at least three replicates. Based on the activities of standards and reference samples, sorption efficiency was calculated. Analysis of variance (ANOVA) and Pearson correlation coefficient (significance level $<0.05)$ were used to estimate differences in the sorption efficiency or bioaccumulation of investigated ions between experimental variants. Values were considered as different when $p<0.05$.

\section{Results and Discussion}

\section{Characteristics of Sorption: Effect of NPs Concentration}

To characterize the sorption capacity of NPs, the sorption efficiency depending on the size and concentration of NPs, time, temperature, $\mathrm{pH}$, and presence of organic matter was investigated as the first step of the study. The dependence of $\mathrm{Zn}$ and $\mathrm{Sr}$ adsorption efficiencies of different-sized $\mathrm{ZnO}$ (50 and $100 \mathrm{~nm}$ ) and $\mathrm{TiO}_{2}(25$ and $100 \mathrm{~nm})$ NPs on the concentration of NPs is shown in Fig. 1. Sorption efficiencies of $\mathrm{Zn}$ and $\mathrm{Sr}$ differ for investigated nanoparticles. Between the two ions, the lowest sorption efficiency (max. $13 \%$ ) was found for $25 \mathrm{~nm} \mathrm{TiO}_{2}$ NPs. Large-sized NPs of $\mathrm{TiO}_{2}(100 \mathrm{~nm})$ have shown better sorption capacity toward investigated ions and reach the value of 48 and $37 \%$ for $\mathrm{Sr}$ and $\mathrm{Zn}$, respectively. Some differences were found in the sorption of investigated ions in the case of $\mathrm{ZnO}$ NPs. For both $\mathrm{Sr}$ and $\mathrm{Zn}$, the sorption efficiency was size-independent, in practice. Nanoparticles of $\mathrm{ZnO}$ remove about $40-45 \%$ of strontium and nearly $90 \%$ of zinc from the solution. Some different mechanisms of metal ion sorption as ion exchange or adsorption may occur. One of the possibilities is that the ions replace exchangeable cations, for example, hydroxyl groups. Such mechanism was postulated for sorption of $\mathrm{Zn}$ (II), $\mathrm{Cd}$ (II), and $\mathrm{Hg}$ (II) onto $\mathrm{ZnO}$ nanoparticles (Sheela et al. 2012). Difference in physical and chemical properties of $\mathrm{Sr}$ and $\mathrm{Zn}$ will explain the observed differences in sorption efficiency.

In accordance with the expectation in the range of lowstudied concentrations (0.01-1 $\mathrm{g} \mathrm{L}^{-1}$ ), an increase of $\mathrm{Sr}$ and $\mathrm{Zn}$ sorption efficiency with an increase in the concentration of $\mathrm{TiO}_{2} 100 \mathrm{~nm}, \mathrm{ZnO} 50 \mathrm{~nm}$, and $\mathrm{ZnO} 100 \mathrm{~nm}$ 

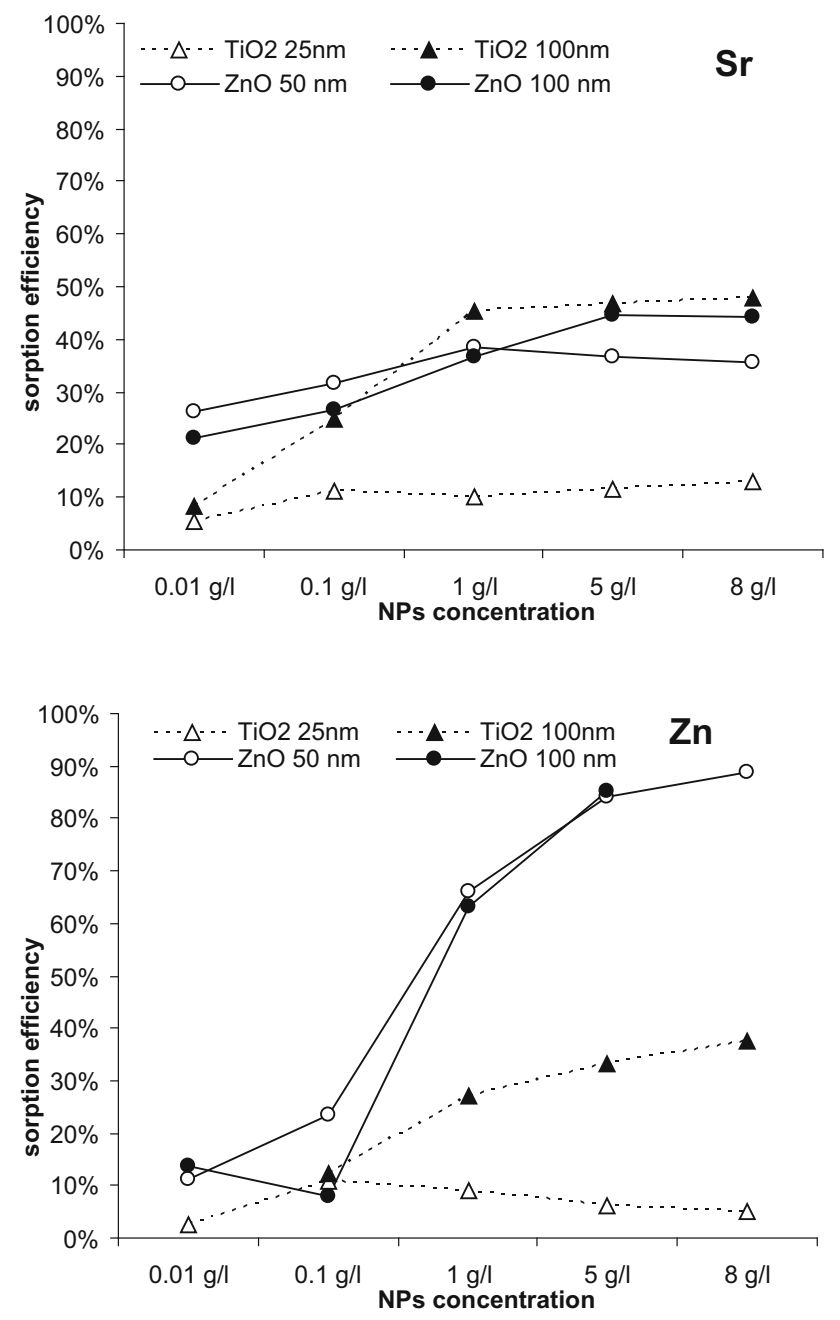

Fig. 1 Sorption efficiency of $\mathrm{Sr}$ and $\mathrm{Zn}$ for different concentrations of $\mathrm{TiO}_{2} 25 \mathrm{~nm}, \mathrm{TiO}_{2} 100 \mathrm{~nm}, \mathrm{ZnO} 50 \mathrm{~nm}$, and $\mathrm{ZnO} 100 \mathrm{~nm}$ NPs $(\mathrm{SD} \leq 5 \%)$

NPs is observed; with increasing sorbent concentration, the available surface sites increases. Similar relationship was found by Engates and Shipley (2011). However, at higher concentrations of $\mathrm{TiO}_{2} 100 \mathrm{~nm}, \mathrm{ZnO} 50 \mathrm{~nm}$, and $\mathrm{ZnO}$ $100 \mathrm{~nm} \mathrm{NPs}\left(>1 \mathrm{~g} \mathrm{~L}^{-1}\right)$, the sorption of $\mathrm{Sr}$ was independent of the sorbent concentration. Sorption is controlled by the nature of the adsorbent and charge of ions and availability. We can expect that at some relatively higher concentrations, the surface properties of NPs are changed, preventing more effective sorption of ions. Additionally, aggregation in concentrated solutions is much more probable and it results in the reduction of surface available for metal ions. In solution of NPs with relatively higher density, some limitations in the diffusion of ions are also possible. More physicochemical studies at particle level must be undertaken in the future to find the explanation for the observed phenomenon. Different observation was made for $\mathrm{Zn}$ sorption at a higher concentration of $\mathrm{TiO}_{2} 100 \mathrm{~nm}$,
$\mathrm{ZnO}$ 50, and $\mathrm{ZnO} 100 \mathrm{~nm}$ NPs. The lowest sorption efficiency was observed for $\mathrm{TiO}_{2} 100 \mathrm{~nm}$ NPs in comparison with both $\mathrm{ZnO} \mathrm{NPs}$; however, the sorption efficiency for the mentioned NPs increases with their concentration. For the smallest investigated $\mathrm{NPs}, \mathrm{TiO}_{2} 25 \mathrm{~nm}$, the sorption capacity was least efficient and some dependence on the concentration was observed.

\section{Characteristics of Sorption: Effect of Sorption Time and Temperature}

In contrast to concentration and particle size, sorption time in the studied range $(0-24 \mathrm{~h})$ was not a factor affecting the sorption efficiency. The percentage of adsorbed ions was the same after $24 \mathrm{~h}$ of experiments when the NPs were separated from ions just after mixing (sorption time $<60 \mathrm{~s}$ was limited only by the time required for laboratory operations). Thus, adsorption is the only process, which occurred rapidly. Similar observation was made by Engates and Shipley (2011), while investigating sorption of some divalent metal ions on $\mathrm{ZnO}$ NPs.

The adsorption of metal ions was also examined with regard to the function of temperature (Fig. 2), which is a very important factor affecting the sorption processes. The experimental results showed that $\mathrm{Sr}$ sorption onto $\mathrm{TiO}_{2} 100 \mathrm{~nm}, \mathrm{ZnO} 50$, and $\mathrm{ZnO} 100 \mathrm{~nm}$ NPs does not depend on the temperature in the studied range $5-90{ }^{\circ} \mathrm{C}$. Only for the smallest NPs of interest- $\mathrm{TiO}_{2} 25 \mathrm{~nm}-$ the percentage of adsorbed $\mathrm{Sr}$ ions increased twice, when the temperature changed from 30 to $90{ }^{\circ} \mathrm{C}$. In contrast to $\mathrm{Sr}$, the sorption of $\mathrm{Zn}$ ions increased with the temperature for all investigated NPs, indicating that the adsorption of metal ions onto $\mathrm{ZnO}$ is an endothermic process. This might attribute to the increased ion mobility and collision efficiency between the ions and the nanoparticles with the increasing temperature. De-protonation reactions were easy at high temperature and the amount of non-protonated groups on the nanoparticle surface increased. The results are contrary to the data published by Sheela et al. (2012); however, the size and preparation of the NPs and the sorption conditions were different, which can result in different observations.

\section{Characteristics of Sorption: Effect of pH}

One of the most important factors affecting the chemistry of both, NPs as an adsorbent and metal ion, is the $\mathrm{pH}$ of the solution. Sorption efficiency of $\mathrm{Zn}$ and $\mathrm{Sr}$ was determined under acidic, neutral, and alkaline conditions (Fig. 3). It was assumed that the sorption capacity of NPs increased with $\mathrm{pH}$ within the range $2-8$. At the highest investigated $\mathrm{pH} 10$, some differences between sorption of $\mathrm{Sr}$ and $\mathrm{Zn}$ were observed. The percentage of $\mathrm{Zn}$ and $\mathrm{Sr}$ ions adsorbed 

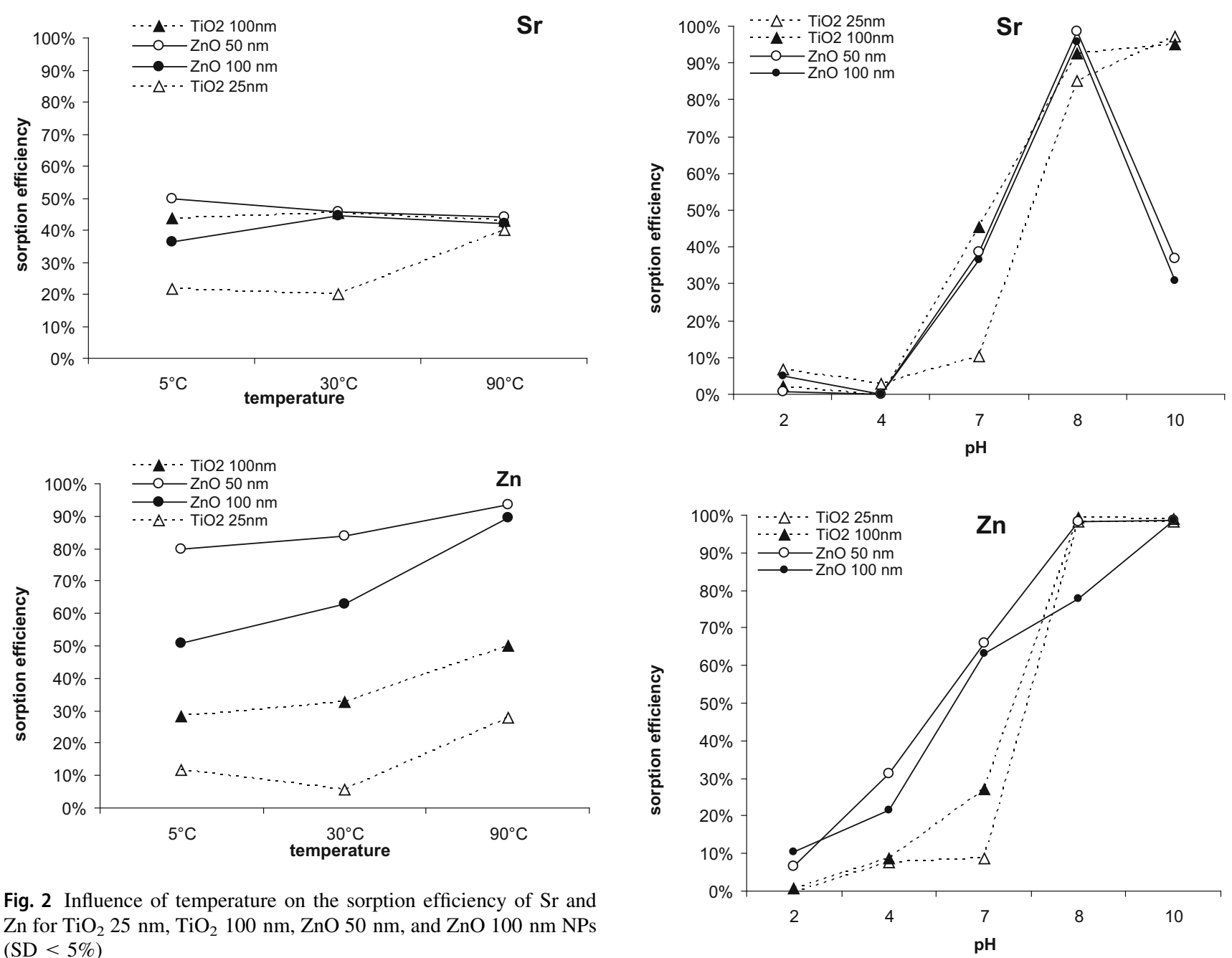

Influence of temperature on the sorption efficiency of $\mathrm{Sr}$ and $\mathrm{Zn}$ for $\mathrm{TiO}_{2} 25 \mathrm{~nm}, \mathrm{TiO}_{2} 100 \mathrm{~nm}, \mathrm{ZnO} 50 \mathrm{~nm}$, and $\mathrm{ZnO} 100 \mathrm{~nm} \mathrm{NPs}$ $(\mathrm{SD} \leq 5 \%)$

onto $\mathrm{TiO}_{2}$ NPs was higher or comparable with the results recorded for $\mathrm{pH}$ 8. Similar relation was observed for $\mathrm{Zn}$ sorption onto $\mathrm{ZnO} \mathrm{NPs}$, while the sorption of $\mathrm{Sr}$ under the same conditions was significantly reduced to about 62 and $67 \%$ for $\mathrm{ZnO} 50 \mathrm{~nm}$ and $\mathrm{ZnO} 100 \mathrm{~nm}$, respectively. Observed difference in the behavior of $\mathrm{Sr}$ and $\mathrm{Zn}$ ions at relatively higher $\mathrm{pH}$ can be explained by their chemical characterSr had alkaline-whereas $\mathrm{Zn}$ had amphoteric properties. The chemistry of the adsorbent surface is also $\mathrm{pH}$ dependent. For the lowest $\mathrm{pH}$, we can expect that some dissolution of NPs occurs. Additionally, the sorbent surface is covered by $\mathrm{H}^{+}$ions. Consequently, the efficiency of sorption is negligible. Increase of $\mathrm{pH}$ results in change in the surface properties of NPs; finally, in alkaline $\mathrm{pH}$, there are reactions of hydroxide ions with hydrous metal oxides. Detailed discussion of the possible processes occurring on the metal oxide nanoparticle surface as an effect of $\mathrm{pH}$ change can be found in the work of Sheela et al. (2012).

Fig. 3 Influence of $\mathrm{pH}$ on the sorption efficiency of $\mathrm{Sr}$ and $\mathrm{Zn}$ for $\mathrm{TiO}_{2} 25 \mathrm{~nm}, \mathrm{TiO}_{2} 100 \mathrm{~nm}, \mathrm{ZnO} 50 \mathrm{~nm}$, and $\mathrm{ZnO} 100 \mathrm{~nm}$ NPs $(\mathrm{SD} \leq 5 \%)$

\section{Characteristics of Sorption: Effect of Humic Acids}

The above-presented result was not in the context of finding optimum conditions for the sorption of $\mathrm{Zn}$ and $\mathrm{Sr}$ ions onto metal oxide nanoparticles, but mainly based on the characteristic of sorption under different conditions from the perspective of the processes and interactions, which can take place in the natural aquatic environment affecting the bioaccumulation of the metal ions. To complete the study, the influence of organic matter on the sorption efficiency was examined using humic acids present in natural waters as example compounds (Fig. 4). The results have shown that $\mathrm{Sr}$ and $\mathrm{Zn}$ sorption onto both investigated $\mathrm{ZnO}$ NPs were not affected by the humic acids at applied concentration alike, at short (15 $\mathrm{min})$ as well as long $(24 \mathrm{~h})$ interactions. Different observation was found for $\mathrm{TiO}_{2}$ NPs. Sorption efficiency of $\mathrm{Sr}$ on $\mathrm{TiO}_{2} 25 \mathrm{~nm}$ increased from about 10 to $40-50 \%$ after addition of humic 

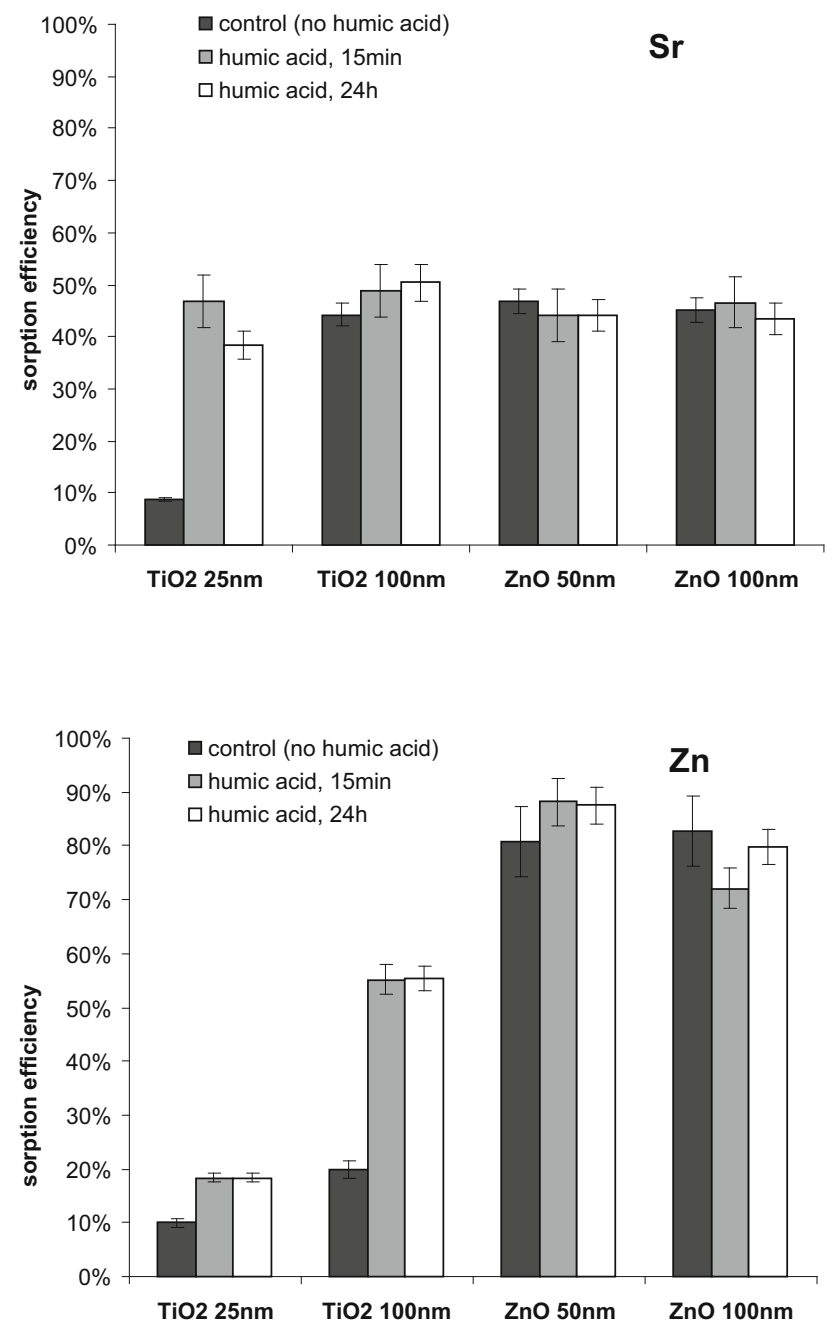

Fig. 4 Influence of humic acids on the sorption efficiency of $\mathrm{Sr}$ and $\mathrm{Zn}$ for $\mathrm{TiO}_{2} 25 \mathrm{~nm}, \mathrm{TiO}_{2} 100 \mathrm{~nm}, \mathrm{ZnO} 50 \mathrm{~nm}$ and $\mathrm{ZnO} 100 \mathrm{~nm} \mathrm{NPs}$

acids. For $\mathrm{Zn}$ ions, this increase was much lower, but still significant (from 10 to $18 \%$ ). Definitely, a greater effect was observed for $\mathrm{Zn}$ sorption onto $\mathrm{TiO}_{2} 100 \mathrm{~nm}$; addition of humic acids caused the increase of sorption efficiency from 20 to 50\%. Sorption of Sr onto NPs of $\mathrm{TiO}_{2} 100 \mathrm{~nm}$ was not affected by humic acids. NPs have a strong tendency to agglomerate. The presence of organic matter provides a means of controlling the state of aggregation by forming a charged external interaction with the nanoparticle surface and improving the steric stability of the system (Grillo et al. 2015). After having interacted with humic acids NPs aggregates could be broken down and the hydrodynamic diameter of NPs should be much lower than the aggregate state (Wang et al. 2016a, b). Increased sorption capacity of nanoparticles in the presence of humic acids may be due to: increased available surface area resulting from higher dispersion and disaggregation and increasing electrostatic attraction. The results again confirmed that sorption depends on the chemical composition of the medium, which affects the chemical properties of both ions and sorbents.

\section{Effect of Nanoparticles on Bioaccumulation of Divalent lons in Plants}

The presented study has undoubtedly shown that NPs can adsorb metal ions present in the water. It also shows that sorption strongly depends on the $\mathrm{pH}$, chemical composition, temperature, or concentrations of NPs, and that under real conditions sorption will be different for different aquatic ecosystems. The question of whether sorption can affect bioavailability of some essential or toxic elements is still open.

The final step of the presented study focused on the examination of the influence of the metal oxide nanoparticles on the bioaccumulation of selected divalent metal ions by aquatic plants: $S$. natans and E. canadensis. Results are presented in Fig. 5.

Bioaccumulation of $\mathrm{Sr}$ in E. canadensis was reduced by $\mathrm{NPs}$ of $\mathrm{TiO}_{2} 100 \mathrm{~nm}, \mathrm{ZnO} 50 \mathrm{~nm}$, and $\mathrm{ZnO} 100 \mathrm{~nm}$ at concentrations $\left(1 \mathrm{~g} \mathrm{~L}^{-1}\right)$ of about 38,47 , and $49 \%$, respectively. Nanoparticles of $\mathrm{TiO}_{2} 25 \mathrm{~nm}$ have negligible effect. The statistical analysis of the results of bioaccumulation of $\mathrm{Sr}$ in E. canadensis in the presence of NPs at $0.1 \mathrm{~g} \mathrm{~L}^{-1}$ has shown that differences between particular results are statistically insignificant. Thus, bioavailability of Sr under applied conditions was not affected by NPs. The results of $\mathrm{Sr}$ accumulation in $\mathrm{S}$. natans were similar. Lower concentration $\left(0.1 \mathrm{~g} \mathrm{~L}^{-1}\right)$ of investigated NPs has not affected the bioaccumulation of Sr; NPs of $\mathrm{TiO}_{2}$ $25 \mathrm{~nm}, \mathrm{TiO}_{2} 100 \mathrm{~nm}, \mathrm{ZnO} 50 \mathrm{~nm}$, and $\mathrm{ZnO} 100 \mathrm{~nm}$ at $1 \mathrm{~g} \mathrm{~L}^{-1}$ of concentration have reduced the accumulation by $40,26,22$, and $23 \%$, respectively. Bioavailability of $\mathrm{Zn}$ was affected the most by NPs of $\mathrm{ZnO}$. E. canadensis accumulated about 45 and $55 \%$ less $\mathrm{ZnO} 50 \mathrm{~nm}$ and $\mathrm{ZnO}$ $100 \mathrm{~nm}$, respectively, at $0.1 \mathrm{~g} \mathrm{~L}^{-1}$. Observed reduction in the bioaccumulation of $\mathrm{Zn}$ was significantly higher for NPs at $1 \mathrm{~g} \mathrm{~L}^{-1}$ concentration and amounted to 77 and $68 \%$ for $\mathrm{ZnO} 50 \mathrm{~nm}$ and $\mathrm{ZnO} 100 \mathrm{~nm}$, respectively. Some amount of reduction in the bioavailability of $\mathrm{Zn}$ by $\mathrm{TiO}_{2} 25 \mathrm{~nm}$ NPs at 0.1 and $1 \mathrm{~g} \mathrm{~L}^{-1}$ concentrations was observed (22 and $48 \%$, respectively); however, no effect was noticed for $\mathrm{TiO}_{2} 100 \mathrm{~nm}$. Definitely, a different effect on the bioaccumulation of $\mathrm{Zn}$ was found for $S$. natans. Addition of $\mathrm{ZnO}$ NPs caused an increase of $\mathrm{Zn}$ bioaccumulation by 92 and $45 \%$ for $\mathrm{ZnO} 50 \mathrm{~nm}$ and $\mathrm{ZnO} 100 \mathrm{~nm}$, respectively. No effect was observed for both the investigated $\mathrm{TiO}_{2} \mathrm{NPs}$ at $0.1 \mathrm{~g} \mathrm{~L}^{-1}$ and for all investigated NPs at $1 \mathrm{~g} \mathrm{~L}^{-1}$.

The presented results show that NPs affect the bioaccumulation of metal ions. Predominant reduction in the metal ion uptake was observed. The effect depends on the chemical composition, size and concentration of NPs, and 

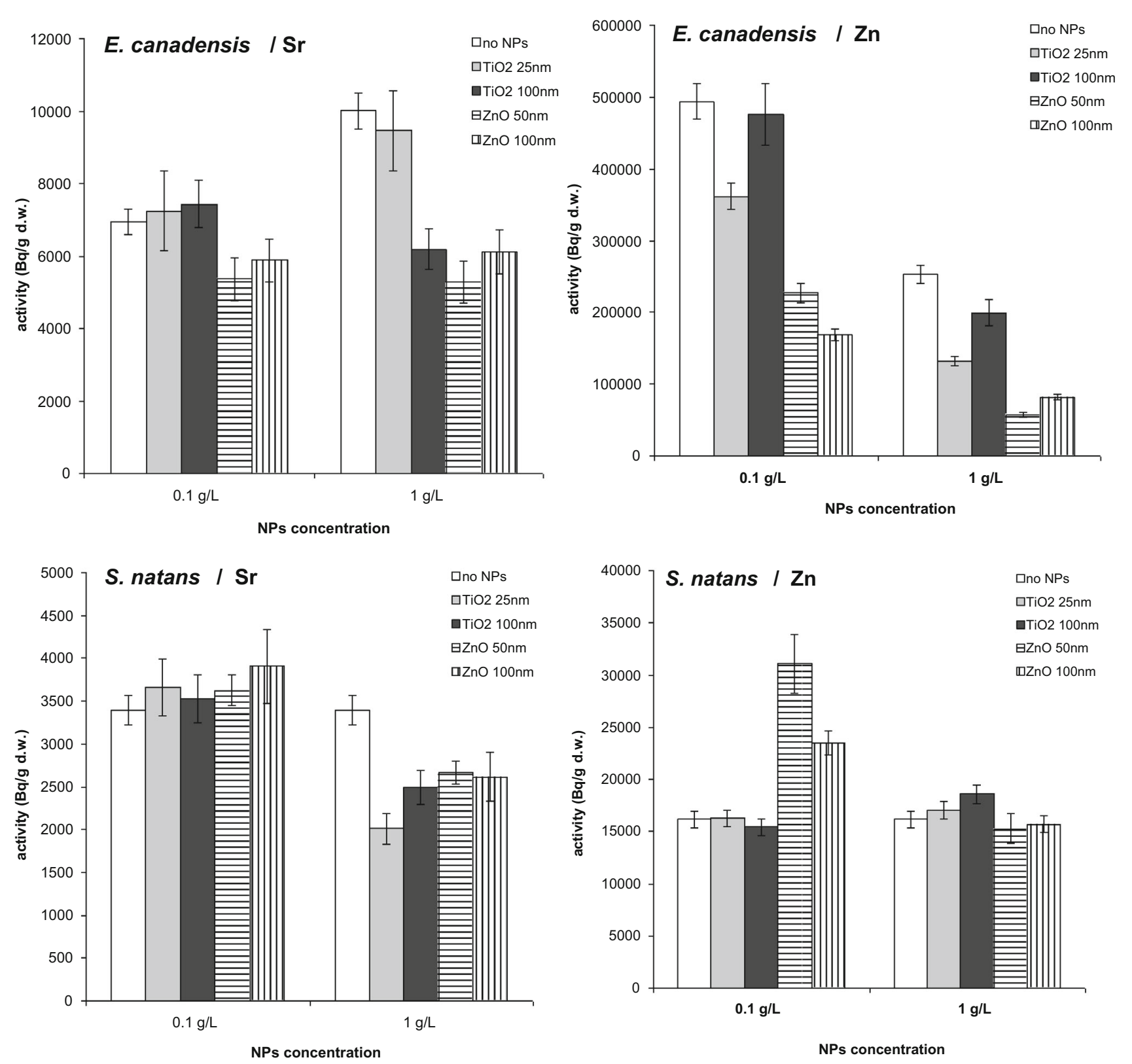

Fig. 5 Bioaccumulation of $\mathrm{Sr}$ and $\mathrm{Zn}$ by $S$. natans and E. canadensis in the presence of $\mathrm{TiO}_{2} 25 \mathrm{~nm}, \mathrm{TiO}_{2} 100 \mathrm{~nm}, \mathrm{ZnO} 50 \mathrm{~nm}$, and $\mathrm{ZnO}$ $100 \mathrm{~nm}$ NPs

the chemical properties of the ions. As the results of metal ion sorption onto NPs have shown, under some conducive conditions, even $90 \%$ of ions can be removed from the solution by sorption processes. In consequence, the bioavailability of ions is reduced. Adsorption of NPs onto the root surface, resulting in the inhibition of uptake, can also be the possible mechanism for the reduction of bioaccumulation. However, sorption of ions onto NPs previously adsorbed on the root surface or uptake of NPs together with ions adsorbed cannot be excluded. Another possibility can be the influence of NPs on the transport systems in plants by the formation of new and large-sized pores and routes, causing an increase of ion uptake. It is also probable that several of the mentioned mechanisms by NPs, which modify the bioaccumulation of metal ions, occur. The next important factor affecting the influence of NPs on the bioaccumulation of ions by plants is the variability in uptake mechanism, which is dependent on physiological, anatomical, and morphological diversities among particular plants species. In our study, we have employed two different plant species: E. canadensis, which is a perennial aquatic plant that lives entirely underwater and $S$. natans, which is an annual aquatic floating fern. $S$. natans has the ability to change the $\mathrm{pH}$ of the water nearby 
the roots. As it can be seen, from the results presented in Fig. 5, the concentration of the accumulated $\mathrm{Zn}$ and $\mathrm{Sr}$ was much higher in case of E. canadensis. These differences between the plant species explain the different observed effects of NPs on bioaccumulation of ions.

\section{Summary}

The influence of NPs on the chemical and physical behavior of water components should be considered during the risk assessment of NP contamination of aquatic environment. One of the possible effects caused by NPs is the modification of metal-ion uptake by direct NP-metal ion reaction, including adsorption of ions onto the surface of NPs. Our study showed that NPs of titanium and zinc oxides have significant sorption capacity toward divalent ions of $\mathrm{Zn}$ and $\mathrm{Sr}$. Influence of particle size and concentration, sorption temperature, $\mathrm{pH}$, and time on the adsorption efficiency was documented. The examination of the bioaccumulation of $\mathrm{Zn}$ (II) and $\mathrm{Sr}$ (II) ions by S. natans and E. canadensis in the presence of metal oxide nanoparticles has led to the conclusion that NPs affect the bioaccumulation of metal ions. The effect depends on the chemical composition, size, and concentration of NPs, and the chemical properties of the ions and plant species. Sorption of ions onto the surface of NPs is one of the possible mechanisms of ion bioavailability reduction. Nevertheless, some other mechanisms are also possible. The results have shown that NPs can modify the bioaccumulation of ions. The effect is positive if ions are toxic, but it is negative if the uptake of essential ions is reduced. Further, more detailed studies must be undertaken to explain the mechanisms responsible for the modification of ion uptake by NPs in aquatic plants.

Acknowledgements This study was supported by the National Science Center, Poland, Grant no. 2013/09/B/NZ8/03295.

Open Access This article is distributed under the terms of the Creative Commons Attribution 4.0 International License (http://creative commons.org/licenses/by/4.0/), which permits unrestricted use, distribution, and reproduction in any medium, provided you give appropriate credit to the original author(s) and the source, provide a link to the Creative Commons license, and indicate if changes were made.

\section{References}

Alkilany AM, Murphy CJ (2010) Toxicity and cellular uptake of gold nanoparticles: what we have learned so far? J Nanopart Res 12:2313-2333

Asztemborska M, Jakubiak M, Książyk M, Stęborowski R, Polskowska-Motrenko H, Bystrzejewska-Piotrowska G (2014) Silver nanoparticles accumulation by aquatic organisms-neutron activation as a tool for the environmental fate of nanoparticles tracing. Nukleonika 59(4):169-173

Asztemborska M, Stęborowski R, Kowalska J, BystrzejewskaPiotrowska G (2015a) Accumulation of aluminium by plants expose to nano- and micro-sized particles of $\mathrm{Al}_{2} \mathrm{O}_{3}$. Int $\mathrm{J}$ Environ Res 9(1):109-116

Asztemborska M, Stęborowski R, Kowalska J, BystrzejewskaPiotrowska G (2015b) Accumulation of platinum nanoparticles by Sinapis alba and Lepidium sativum plants. Water Air Soil Pollut 226(4):126

Asztemborska M, Jakubiak M, Rykaczewska M, Bembenek M, Stęborowski R, Bystrzejewska-Piotrowska G (2016) Mycoextraction of radiolabeled cesium and strontium by Pleurotus eryngii mycelia in the presence of alumina nanoparticles: sorption and accumulation studies. J Environ Rad 164:190-196

Baek YW, An YJ (2011) Microbial toxicity of metal oxide nanoparticles $\left(\mathrm{CuO}, \mathrm{NiO}, \mathrm{ZnO}\right.$, and $\left.\mathrm{Sb}_{2} \mathrm{O}_{3}\right)$ to Escherichia coli, Bacillus subtilis, and Streptococcus aureus. Sci Total Environ 409:1603-1608

Baker TJ, Tyler CR, Galloway TS (2014) Impacts of metal and metal oxide nanoparticles on marine organisms. Environ Pollut 186:257-271

Baun A, Sørensen SN, Rasmussen RF, Hartmann NB, Koch CB (2009) Toxicity and bioaccumulation of xenobiotic organic compounds in the presence of aqueous suspensions of aggregates of nano-C60. Aquat Toxicol 86:379-387

Behnajady MA, Bimeghdar S (2014) Synthesis of mesoporous NiO nanoparticles and their application in the adsorption of $\mathrm{Cr}(\mathrm{VI})$. Chem Eng J 239:105-113

Bystrzejewska-Piotrowska G, Golimowski J, Urban PL (2009) Nanoparticles: their potential toxicity, waste and environmental management. Waste Manage 29(2009):2587-2595

Bystrzejewska-Piotrowska G, Asztemborska M, Steborowski R, Ryniewicz J, Polkowska-Motrenko H, Danko B (2012a) Application of neutron activation for investigation of $\mathrm{Fe}_{3} \mathrm{O}_{4}$ nanoparticles accumulation by plants. Nukleonika 57(3):427-430

Bystrzejewska-Piotrowska G, Asztemborska M, Giska I, Mikoszewski A (2012b) Influence of earthworms on extractability of metals from soils contaminated with $\mathrm{Al}_{2} \mathrm{O}_{3}, \mathrm{TiO}_{2}, \mathrm{Zn}$, and $\mathrm{ZnO}$ nanoparticles and microparticles of $\mathrm{Al}_{2} \mathrm{O}_{3}$. Pol $\mathrm{J}$ Environ Stud 21(2):313-319

Engates KE, Shipley HJ (2011) Adsorption of Pb, Cd, Cu, Zn, and Ni to titanium dioxide nanoparticles: effect of particle size, solid concentration, and exhaustion. Environ Sci Pollut Res 18(3):386-395

Fan W, Cui M, Liu H, Wang C, Shi Z, Tan C, Yang X (2011) Nano$\mathrm{TiO}_{2}$ enhances the toxicity of copper in natural water to Daphnia magna. Environ Pollut 159:729-734

Giraldo L, Erto A, Moreno-Piraján JC (2013) Magnetite nanoparticles for removal of heavy metals from aqueous solutions: synthesis and characterization. Adsorption 19(2-4):465-474

Grillo R, Rosa AH, Fraceto LF (2015) Engineered nanoparticles and organic matter: a review of the state-of-the-art. Chemosphere 119:608-619

Jakubiak M, Giska I, Asztemborska M, Bystrzejewska-Piotrowska G (2014) Bioaccumulation and biosorption of inorganic nanoparticles: factors affecting the efficiency of nanoparticle mycoextraction by liquid-grown mycelia of Pleurotus eryngii and Trametes versicolor. Mycol Prog 13(3):525-532

Jiménez-Lamana J, Wojcieszek J, Jakubiak M, Asztemborska M, Szpunar J (2016) Single particle ICP-MS characterization of platinum nanoparticles uptake and bioaccumulation by Lepidium sativum and Sinapis alba plants. J Anal At Spectrom 31:2321-2329

Książyk M, Asztemborska M, Stęborowski R, BystrzejewskaPiotrowska G (2015) Toxic effect of silver and platinum 
nanoparticles toward the freshwater microalga Pseudokirchneriella subcapitata. Bull Environ Contam Toxicol 94(5):554-558

Li YH, Ding J, Luan ZK, Di ZC, Zhu YF, Xu CL, Wu DH, Wei BQ (2003) Competitive adsorption of $\mathrm{Pb}^{2+} \mathrm{Cu}^{2+}$ and $\mathrm{Cd}^{2+}$ ions from aqueous solutions by multiwalled carbon nanotubes. Carbon 41(14):2787-2792

Liu Y, Fu R, Sun Y, Zhou X, Baig SA, Xu X (2016) Multifunctional nanocomposites $\mathrm{Fe} 3 \mathrm{O} 4 @ \mathrm{SiO} 2$-EDTA for $\mathrm{Pb}$ (II) and $\mathrm{Cu}$ (II) removal from aqueous solutions. Appl Surf Sci 369:267-276

Ma X, Geiser-Lee J, Deng Y, Kolmakov A (2010) Interactions between engineered nanoparticles (ENPs) and plants: phytotoxicity, uptake and accumulation. Sci Total Environ 408(16):3053-3061

Mahdavi S, Jalali M, Afkhami A (2013) Heavy metals removal from aqueous solutions using $\mathrm{TiO}_{2}, \mathrm{MgO}$, and $\mathrm{Al}_{2} \mathrm{O}_{3}$ nanoparticles. Chem Eng Commun 200(3):448-470

Sadiq IM, Dalai S, Chandrasekaran N, Mukherjee A (2011) Ecotoxicity study of titania $\left(\mathrm{TiO}_{2}\right)$ NPs on two microalgae species: Scenedesmus sp. and Chlorella sp. Ecotox Environ Safety 74:1180-1187

Saleh TA (2016) Nanocomposite of carbon nanotubes/silica nanoparticles and their use for adsorption of $\mathrm{Pb}(\mathrm{II})$ : from surface properties to sorption mechanism. Desalin Water Treat 57(23):10730-10744

Sheela T, Nayaka YA, Viswanatha R, Basavanna S, Venkatesha TG (2012) Kinetics and thermodynamics studies on the adsorption of $\mathrm{Zn}$ (II), Cd (II) and $\mathrm{Hg}$ (II) from aqueous solution using zinc oxide nanoparticles. Powder Technol 217:163-170

Sun H, Zhang X, Niu Q, Chen Y, Crittenden JC (2007) Enhanced accumulation of arsenate in carp in the presence of titanium dioxide nanoparticles. Water Air Soil Pollut 178:245-254
Tan C, Wang WX (2014) Modification of metal bioaccumulation and toxicity in Daphnia magna by titanium dioxide nanoparticles. Environ Pollut 186:36-42

Thwala M, Klaine SJ, Musee N (2016) Interactions of metal-based engineered nanoparticles with aquatic higher plants: a review of the state of current knowledge. Environ Toxicol Chem 35(7): 1677-1694

Tian S, Zhang Y, Song C, Zhu X, Xing B (2014) Titanium dioxide nanoparticles as carrier facilitate bioaccumulation of phenanthrene in marine bivalve, ark shell (Scapharca subcrenata). Environ Pollut 192:59-64

Wang Z, Xu J, Hu Y, Zhao H, Zhou J, Liu Y, Xu X (2016a) Functional nanomaterials: study on aqueous $\mathrm{Hg}$ (II) adsorption by magnetic $\mathrm{Fe}_{3} \mathrm{O}_{4} @ \mathrm{SiO}_{2}-\mathrm{SH}$ nanoparticles. J Taiwan Inst Chem E 60:394-402

Wang Z, Zhang L, Zhao J, Xing B (2016b) Environmental processes and toxicity of metallic nanoparticles in aquatic systems as affected by natural organic matter. Environ Sci Nano 3:240-255

Yang Y, Qin Z, Zeng W, Yang T, Cao Y, Mei X, Kuang Y (2016) Toxicity assessment of nanoparticles in various systems and organs. Nanotechnol. https://doi.org/10.1515/ntrev-2016-0047

Yen CH, Lien HL, Chung JS, Yeh HD (2017) Adsorption of precious metals in water by dendrimer modified magnetic nanoparticles. J Hazard Mater 322:215-222

Zhang X, Sun H, Zhang Z, Niu Q, Chen Y, Crittenden JC (2007) Enhanced bioaccumulation of cadmium in carp in the presence of titanium dioxide nanoparticles. Chemosphere 67:160-166

Zoroddu MA, Medici S, Ledda A, Nurchi VM, Lachowicz JI, Peana M (2014) Toxicity of nanoparticles. Curr Med Chem 21:3837-3853 